\title{
EuroTravNet: imported Chagas disease in nine European countries, 2008 to 2009
}

J A Perez-Molina (jose.perezmolina@gmail.com) ${ }^{1}$, A Perez-Ayala ${ }^{1}$, P Parola ${ }^{2}$, Y Jackson³ ${ }^{3}$ S Odolini ${ }^{4}$, R Lopez-Velez ${ }^{1}$, for the EuroTravNet Network ${ }^{5}$

1. Tropical Medicine, Infectious Diseases Service, Hospital Ramón y Cajal, Instituto Ramon Y Cajal De Investigación Sanitaria, Madrid, Spain

2. Department of Infectious and Tropical Diseases, Hôpital Nord, Marseille, France

3. Division of Primary Care Medicine, Department of Community Medicine And Primary Care, University Hospitals of Geneva and Geneva University, Geneva, Switzerland

4. Institute for Infectious and Tropical Disease, University of Brescia, Brescia, Italy

5. http://www.istm.org/eurotravnet/main.html

Citation style for this article:

Perez-Molina JA, Perez-Ayala A, Parola P, Jackson Y, Odolini S, Lopez-Velez R, for the EuroTravNet Network. EuroTravNet: imported Chagas disease in nine European countries, 2008 to 2009

Euro Surveill. 2011;16(37):pii=19966. Available online: http://www.eurosurveillance.org/ViewArticle.aspx?Articleld=19966

Article published on 15 September 2011

In recent years, Chagas disease has emerged as a disease of importance outside of endemic areas, largely as a result of migration. In Europe, clinicians may have to treat infected migrants from endemic areas as well as people with acute infections transmitted congenitally, through organ donation or blood transfusion. We describe here the characteristics of patients diagnosed with chronic Chagas disease at the core clinical sites of the EuroTravNet network during 2008 and 2009. Of the 13,349 people who attended the sites, 124 had chronic Chagas disease. Most ( $96 \%$ ) were born in Bolivia and the median number of months in the country of residence before visiting a EuroTravNet core site was 38 months (quartile $(Q)-Q_{3}: 26-55$ ). The median age of the patients was 35 years $\left(Q_{1}-Q_{3}: 29-45\right)$ and $65 \%$ were female. All but one were seen as outpatients and the most frequent reason for consultation was routine screening. Considering that Chagas disease can be transmitted outside endemic regions and that there is effective treatment for some stages of the infection, all migrants from Latin America (excluding the (aribbean) should be questioned about past exposure to the parasite and should undergo serological testing if infection is suspected.

\section{Background}

Chagas disease is a zoonosis caused by the parasite Trypanosoma cruzi. It is endemic in the American continent, particularly Latin America, being present from the southern United States to Chile and Argentina $[1,2]$. Although the burden of the disease has decreased in the last 20 years in endemic areas due to various control measures, thousands of new cases are diagnosed there each year [1-3] and 28 million people are estimated to be at risk of contracting the disease $[1,2]$. In the American continent, the incidence of chronic T. cruzi infection in 2005 was 8 per 100,000 population for vectorial cases $(n=41,200)$ and 130 per 100,000 births for congenital cases $(n=14,385)$, prevalence was $1.44 \%$ ( $n=8-10$ million) and the mortality rate was $0.0023 \%$ (there were 12,500 deaths) [1]. After acute infection, people remain infected for life if not treated and $20-30 \%$ of chronically infected people will develop organ involvement, predominantly cardiac disease, after 10 to 30 years [2]. In endemic areas of Latin America, Chagas disease is the leading cause of cardiomyopathy and is the main cause of death due to cardiovascular disease in patients aged 30-50 years [4].

In endemic areas, T. cruzi is transmitted to humans by triatomids (known as kissing bugs). However, Chagas disease has emerged outside these areas as a result of travel and migration. As a consequence, imported Chagas disease has been recognised as an emerging public health problem in North America, Western Pacific countries (mainly Australia and Japan) and Europe [5].

Sporadic cases have been described in Europe in the last 20 years arising from acute infection after travel to an endemic area [6], blood transfusion [7], laboratory accident [8], and, most recently, as a result of reactivation in an HIV-coinfected patient [9]. Indeed, in non-endemic countries, blood transfusion is one of the main modes of acquiring the infection, making implementation of screening programmes in at-risk donors advisable in all European blood banks [10].

Since 2000, increasing numbers of cases have been reported in many European countries [11-15]. It has been estimated that during 1999 to 2009 the number of people infected with $T$. cruzi in Europe has exceeded 80,000 , of which more than 4,000 were laboratory confirmed [16]. The most affected countries were Spain, with an estimated 40,000 to 65,000 cases $(3,617$ laboratory-confirmed cases), United Kingdom 14,000 (28 laboratory confirmed), Italy 5,500 to 7,000 (114 laboratory confirmed), Switzerland 3,000 (180 laboratory 
confirmed), France 2,166 (111 laboratory confirmed), Belgium 1,982 (19 laboratory confirmed), Sweden 1,118 (1 laboratory confirmed), Germany 935 (2 laboratory confirmed), Portugal 850 (8 laboratory confirmed), and the Netherlands 480 (7 laboratory confirmed) [16].

Migrants from Latin America accounted for $15 \%$ of all migrants in countries of the European Union in 2008; most of them came from Ecuador, Brazil, Colombia and Bolivia [17]. In many European countries, screening for Chagas disease has now become a frequent reason for consultation, especially at units specialising in tropical medicine or imported infections [11-13,18,19], whereas previously the disease had been practically unknown in these countries. There is a lack of awareness of the disease, which may lead to misdiagnosis. The potential severity of the disease, even if those infected are asymptomatic, should not be underestimated.

This article describes the characteristics of patients diagnosed with Chagas disease during 2008 and 2009 at the core clinical sites of the European Travel Medicine Network (EuroTravNet), a network of clinical specialists in tropical and travel medicine.

\section{EuroTravNet}

This network was founded in 2008 by the International Society of Travel Medicine to assist the European Centre for Disease Prevention and Control (ECDC) in the detection, verification assessment and communication of communicable diseases that can be associated with travel, with a particular emphasis on tropical diseases. It was created by grouping the European sites of Geosentinel, the Global Surveillance Network of the International Society of Travel Medicine and the United States Centres for Disease Prevention and Control.

EuroTravNet has 15 core clinical sites - institutes from nine European countries (France, Germany, Italy, Netherlands, Norway, Spain, Sweden, Switzerland and United Kingdom) - which participate in surveillance of travel-related diseases by collecting epidemiological data of ill travellers or migrants. Data were collected using the surveillance platform and database of the Global Surveillance Network of the International Society of Travel Medicine (GeoSentinel), to which the sites contribute $[12,13]$.

People who presented at a EuroTravNet core site from 1 January 2008 to 31 December 2009 after international travel or migration to Europe were tested. For the purposes of this analysis, we included all those in whom we detected IgG antibodies against $T$. cruzi antigens using at least two different serological methods (usually enzyme-linked immunosorbent assay, indirect immunofluorescence or indirect haemagglutination) and identified them as confirmed chronic Chagas cases. To identify acute cases, a direct method to detect the parasite was used (microhaematocrit, Strout test or Giemsa staining) $[20,21]$.
As for other EuroTravNet analyses [22,23], data that could not be linked to an individual patient were collected using a standardised, anonymised questionnaire and entered by all EuroTravNet core sites into the GeoSentinel database.

We defined a migrant as a person born in a country different from their country of residence and a VFR (visiting friends and relatives) traveller as a person whose primary purpose of travel was to visit friends or relatives and for whom there was a gradient of epidemiological risk between their home and travel destination, regardless of race, ethnicity or administrative/legal status [24].

\section{EuroTravNet data}

A total of 6,957 and 6,392 people who presented with health complaints or for health screening associated with travel or migration were seen at the participating sites in 2008 and 2009, respectively. These 13,349 patients included 1,631 VFR travellers and 1,145 migrants.

Of the 13,349 patients, 124 were infected with T. cruzi: 121 in Spain and three in Switzerland. There were no additional cases reported in the other EuroTrovNet countries during the study period (Germany, France, Italy, Netherlands, Norway, Sweden and United Kingdom). All the patients came from endemic areas and had developed the chronic form of the illness. Most of them had arrived in their country of destination in Europe between 2001 and 2007 and the median time from arrival to their first visit at a EuroTravNet core site was 38 months. Only one patient presented after travel from their country of residence: a Bolivian in their early 305 who had travelled for three weeks to Bolivia in 2008, attended the EuroTravNet site just after their return, and had no evidence of newly acquired acute disease. We consequently consider this as chronic infection of a migrant: there were therefore no cases of Chagas disease associated with travel from a European country.

Demographic data and characteristics of the 124 patients are presented in the Table. Almost all patients (96\%) were born in Bolivia, which was the most probable country of exposure in these cases (determined by physicians on the basis of past epidemiological risk factors). The median age of the patients was 35 years and women accounted for $65 \%$ of all cases.

All patients but one were seen as outpatients, mainly at the Madrid site of EuroTravNet. The most frequent reason for consultation was routine screening (these asymptomatic patients attended for a general health examination) and, for some patients $(n=9)$, Chagas disease was diagnosed after consultation for other related or non-related medical problems such as eosinophilia, constipation, anterior uveitis or musculoskeletal complaints. 
Implications of the EuroTravNet findings

Some one hundred years after its discovery, it is clear that Chagas disease still affects millions in Latin America and is no longer restricted to endemic areas. The majority of $T$. cruzi infected people outside Latin America are actively working, asymptomatic migrant adults, 18-49 years, with chronic infection $[13,14,25]$. Most will have been infected during childhood and therefore, based on the natural course of the disease, these migrants would now be at an age when the first manifestations of visceral involvement may be expected to appear. Furthermore, the high number of women among Latin American migrants means that congenital transmission of $T$. cruzi may be a cause for concern [26]. It has been estimated that the rate of mother-to-child transmission of $T$. cruzi in this population is about $7 \%$ [25]. Physicians in non-endemic countries should therefore be aware during their routine clinical practice of the existence or even the potential transmission of this disease.

A limitation of our analysis is that most data come from one site (Madrid) and that not all European countries are represented in the network. Additionally, only core sites from EuroTravNet contributed to this study. However, the characteristics of the patients in this report are quite similar to those of Chagas patients in Europe [11-14], probably because Spain is by far the most affected European country [16]. The patients were migrants who attended as outpatients, mainly for screening while asymptomatic (93\%), were predominantly female $(65 \%)$, with a median age of 35 years and of Bolivian origin ( $96 \%)$. In fact, Bolivia is the country with the highest prevalence of Chagas disease in Latin America $[1,2]$.

\section{TABLE}

Demographic data and characteristics of Trypanosoma cruzi-infected patients detected through EuroTravNet, 2008-2009 $(n=124)$

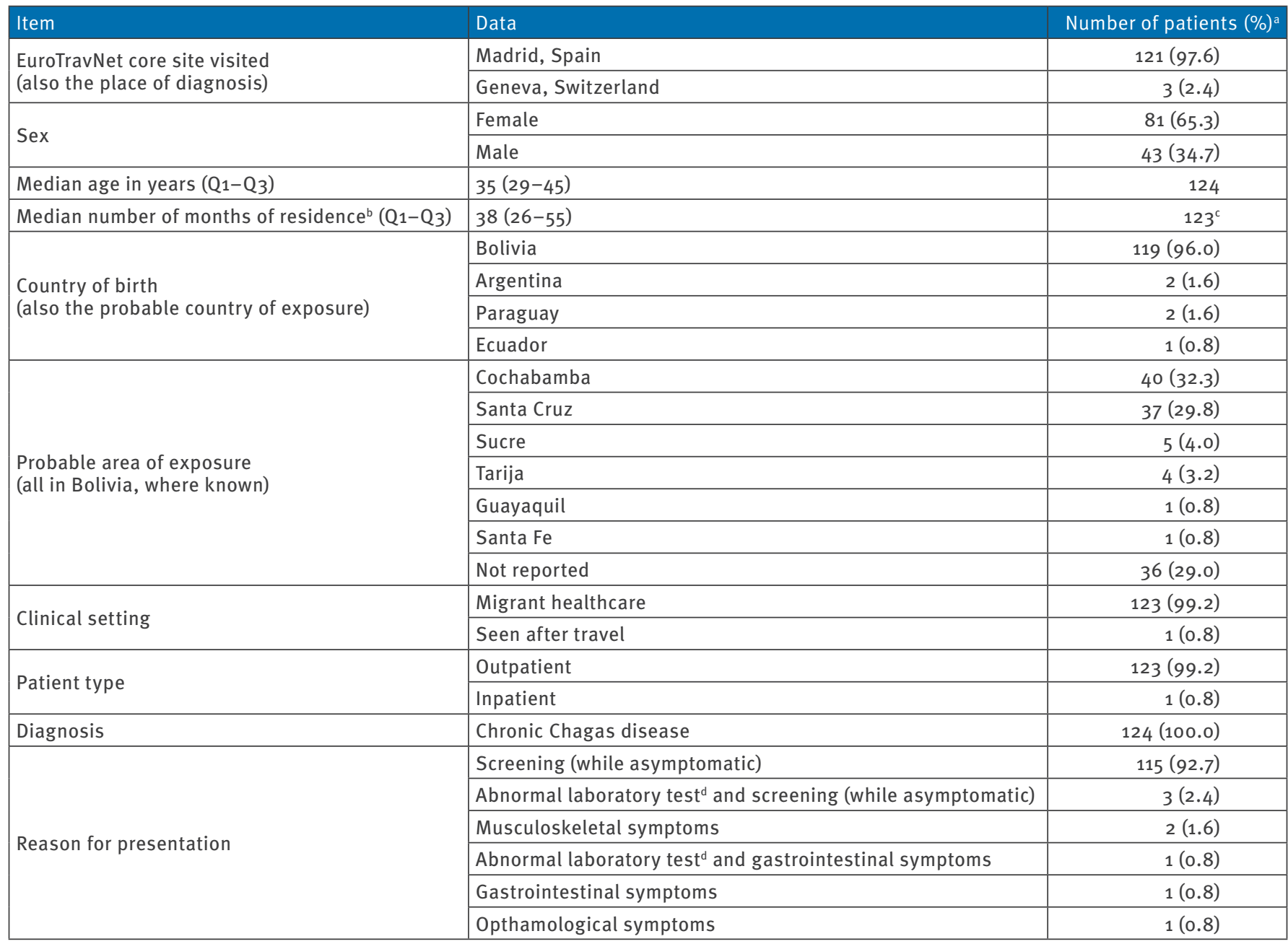

Q: quartile.

a Where appropriate.

b Number of months in the country of residence before diagnosis of Chagas disease.

Data unavailable for one patient.

d Tests detecting, for example, eosinophilia and anaemia, and elevated liver function tests. 
It is noteworthy that the median time between their arrival in their country of residence and the date they first visited the EuroNetTrav site was 38 months. This delay could hinder the early detection and treatment of visceral complications and perinatal infection, and the prevention of congenital transmission

Anti-trypanosomal drug treatment is strongly recommended for all cases of acute, congenital or reactivated infection, and for patients up to 18 years of age with chronic disease $[1,27,28]$. The efficacy of treatment in late chronic infection is doubtful, but treatment should generally be offered to adults aged 19-50 years without advanced heart disease $[1,27,28]$. It is optional for those older than 50 years because benefit of treatment has not been proved in this population [27-29]. Treatment of infected women of childbearing age could also have an additional benefit by decreasing or preventing congenital transmission [30].

Considering that Chagas disease can be transmitted outside endemic regions and that there is effective treatment for some stages of the infection, all migrants from Latin America (excluding the Caribbean) should be questioned about past potential exposure to the parasite and undergo serological testing if infection is suspected. Serological testing is especially indicated for children (as they have a better response to treatment), women of childbearing age and pregnant women (for prevention of mother-to-child transmission), HIVinfected patients or other immunocompromised people (due to potential reactivation of latent infection), and blood or organ donors (because of the risk of acute infection in the recipient). Surveillance networks such as EuroTravNet can play a central role in case detection and, as sentinels, may contribute to the description of trends in imported infections of medical importance

\section{Acknowledgments}

EuroTravNet has been funded through the public tenders 0J/2008/07/08-PROC/2008/019 and 0J/2010/03/16PROC/2010/011 and has been supported by Cooperative Agreement $U_{50}$ Cloo0359 from the United States Centers for Disease Control and Prevention.

\section{References}

1. Pan American Health Organization (PAHO). Estimación cuantitativa de la enfermedad de Chagas en las Américas [Quantitative estimation of Chagas disease in The Americas]. Washington, DC: PAHO; 2006. OPS/HDM/CD/425-06. Spanish.

2. Rassi A Jr, Rassi A, Marin-Neto JA. Chagas disease. Lancet. 2010;375(9723):1388-402.

3. Pan American Health Organization (PAHO). Chagas disease (American trypanosomiasis). Washington, DC: PAHO. [Accessed 1 Dec 2010]. Available from: http://www.paho.org/english/ad/ $\mathrm{dpc} / \mathrm{cd} / \mathrm{chagas.htm}$

4. Rassi Jr A, Rassi A, Marin-Neto JA. Chagas heart disease: pathophysiologic mechanisms, prognostic factors and risk stratification. Mem Inst Oswaldo Cruz. 2009;104 Suppl 1:152-8.

5. Schmunis GA, Yadon ZE. Chagas disease: a Latin American health problem becoming a world health problem. Acta Trop. 2010;115(1-2):14-21.
6. Brisseau JM, Cebron JP, Petit T, Marjolet M, Cuilliere P, Godin J, et al. Chagas' myocarditis imported into France. Lancet. 1988;1(8593):1046.

7. Villalba R, Fornés G, Alvarez MA, Román J, Rubio V, Fernández $M$, et al. Acute Chagas' disease in a recipient of a bone marrow transplant in Spain: case report. Clin Infect Dis. 1992;14(2):594-5.

8. Alvar J. Un caso agudo de enfermedad de Chagas causado por una inoculación accidental de laboratorio [An acute case of Chagas disease due to an accidental laboratory inoculation]. Laboratorio. 1983;76(456):645-8. Spanish.

9. Verdú J, De Paz F, Castaño V, Torrús D, Reus S. Reactivation of Chagas disease with central nervous system involvement: peripheral blood smear evidence. Int J Infect Dis. 2009;13(6):e527-8.

10. Piron M, Vergés M, Muñoz J, Casamitjana N, Sanz S, Maymó RM, et al. Seroprevalence of Trypanosoma cruzi infection in at-risk blood donors in Catalonia (Spain). Transfusion. 2008;48(9):1862-8.

11. Lescure FX, Canestri A, Melliez H, Jauréguiberry S, Develoux $M$, Dorent R, et al. Chagas disease, France. Emerg Infect Dis. 2008;14(4):644-6.

12. Jackson $Y$, Gétaz L, Wolff H, Holst M, Mauris A, Tardin A, et al. Prevalence, clinical staging and risk for blood-borne transmission of Chagas disease among Latin American migrants in Geneva, Switzerland. PLoS Negl Trop Dis. 2010;4(2):e592.

13. Muñoz J, Gómez i Prat J, Gállego M, Gimeno F, Treviño B, LópezChejade $\mathrm{P}$, et al. Clinical profile of Trypanosoma cruzi infection in a non-endemic setting: immigration and Chagas disease in Barcelona (Spain). Acta Trop. 2009;111(1):51-5.

14. Pérez-Ayala A, Pérez-Molina JA, Norman F, Navarro M, MongeMaillo B, Díaz-Menéndez $M$, et al. Chagas disease in Latin American migrants: a Spanish challenge. Clin Microbiol Infect. 2011;17(7):1108-13.

15. Anselmi M, Angheben A, Degani M, Tais S, Spreafico I, Bonifacio E, et al. Imported Chagas disease in Italy: the tip of the iceberg. Description of the first 10 cases treated at the Centre for Tropical Diseases. Abstracts of the 6th European Congress on Tropical Medicine and International Health and 1st Mediterranean Conference on Migration and Travel Health. Trop Med Int Health. 2009;14 (Suppl 2):240. Abstract MC14-222. Available from: http://onlinelibrary.wiley.com/ doi/10.1111/j.1365-3156.2009.02354_3.x/pdf

16. World Health Organization (WHO). Control and prevention of Chagas disease in Europe. Report of a WHO Informal Consultation (jointly organized by WHO headquarters and the WHO Regional Office for Europe). Geneva, Switzerland, 17-18 December 2009. Geneva: WHO; 2010. WHO/HTM/NTD/ IDM/2010.1. Available from: http://www.fac.org.ar/1/comites/ chagas/Chagas_WHO_Technical\%20Report_16_06_10.pdf

17. Herm A. Population and social conditions. Statistics in Focus 98/2008. Eurostat. European Commission. Available from: http://epp.eurostat.ec.europa.eu/cache/ITY OFFPUB/KSSF-08-098/EN/KS-SF-08-098-EN.PDF

18. Pérez de Ayala A, Pérez-Molina JA, Norman F, López-Vélez R. Chagasic cardiomyopathy in immigrants from Latin America to Spain. Emerg Infect Dis. 2009;15(4):607-8.

19. Manzardo C, Treviño B, Gómez i Prat J, Cabezos J, Monguí E, Clavería I, et al. Communicable diseases in the immigrant population attended to in a tropical medicine unit: epidemiological aspects and public health issues. Travel Med Infect Dis. 2008;6(1-2):4-11.

20. Ministério da Saúde. Secretaria de Vigilância em Saúde. [Brazilian Consensus on Chagas disease]. Rev Soc Bras Med Trop. 2005;38 Suppl 3:7-29. Portuguese.

21. Flores-Chávez M, de Fuentes I, Gárate T, Cañavate C. Diagnóstico de laboratorio de la enfermedad de Chagas importada [Laboratory diagnosis of imported Chagas disease]. Enferm Infecc Microbiol Clin. 2007;25(Supl 3):29-37. Spanish. Available from: http://www.seimc.org/control/revisiones/ parasitologia/ccs-2006-parasitologia1.pdf

22. Field V, Gautret P, Schlagenhauf P, Burchard GD, Caumes $E$, Jensenius $M$, et al. Travel and migration associated infectious diseases morbidity in Europe, 2008. BMC Infect Dis. 2010;10:330.

23. Gautret P, Schlagenhauf P, Gaudart J, et al. Multicenter EuroTravNet/GeoSentinel study of travel-related infectious diseases in Europe. Emerg Infect Dis. 2009;15(11):1783-90.

24. Barnett ED, MacPherson DW, Stauffer WM, Loutan L, Hatz CF, Matteelli A, et al. The visiting friends or relatives traveler in the 21st century: time for a new definition. J Travel Med. 2010;17(3):163-70.

25. Muñoz J, Coll O, Juncosa T, Vergés M, del Pino M, Fumado V, et al. Prevalence and vertical transmission of Trypanosoma cruzi 
infection among pregnant Latin American women attending 2 maternity clinics in Barcelona, Spain. Clin Infect Dis.

2009;48(12):1736-40.

26. Soriano Arandes A, Muñoz Gutierrez J, Vergés Navarro M,

Castells Doménech C, Portús Vinyeta M, Gascón Brustenga J.

Prevalence of Chagas disease in the Latin American immigrant population in a primary health centre in Barcelona (Spain). Acta Trop. 2009;112(2):228-30.

27. Bern C, Montgomery SP, Herwaldt BL, Rassi A Jr, Marin-Neto JA, Dantas RO, et al. Evaluation and treatment of chagas disease in the United States: a systematic review. JAMA. 2007;298(18):2171-81.

28. Rodriques Coura J, de Castro SL. A critical review on Chagas disease chemotherapy. Mem Inst Oswaldo Cruz. 2002;97(1):3-24.

29. Pérez-Molina JA, Pérez-Ayala A, Moreno S, Fernández-González MC, Zamora J, López-Velez R. Use of benznidazole to treat chronic Chagas' disease: a systematic review with a metaanalysis. J Antimicrob Chemother. 2009;64(6):1139-47.

30. Sosa-Estani S, Cura E, Velazquez E, Yampotis C, Segura EL. Etiological treatment of young women infected with Trypanosoma cruzi, and prevention of congenital transmission. Rev Soc Bras Med Trop. 2009;42(5):484-7 